\title{
Kasvatusest üleilmsete kriiside ajastul
}

\author{
Tiiu Kuurme ${ }^{\mathrm{a}}$ \\ ${ }^{a}$ Tallinna Ülikooli haridusteaduste instituut
}

\begin{abstract}
Värri, V.-M. (2018). Kasvatus ekokriisin aikakaudella. Tampere: Vastapaino.
\end{abstract}

Kasvatuse mõiste on Eestis nii ametlikest kui ka akadeemilistest tekstidest taandumas. Temast kas vaikitakse või vihjatakse, et tegu on vananenud mõistega. Soome teadlased aga kasvatuse tähtsuses ei kahtle. Kogu haridust ja kasvatust hõlmavat teadmust kokku võttev teadustermin on soomlastel endiselt kasvatustiede. Meiega ühine keeleline kuju - kasvatus - viitab mõiste iidsele päritolule ehk olemasolule juba läänemeresoome algkeeles. Kui rikkalik ning mitmekihiline on tegelikkus selle mõiste taga tänapäeval ja mis kasvatusest sõltub, see avanebki lugejale Värri raamatut lugedes.

Kasvatusest räägitakse eesti ja soome kontekstis erineval viisil, ehkki sisutähendus on neil sama. Soomes tuntud ja tunnustatud kasvatusfilosoofi VeliMatti Värri 2018. aastal Soome parima teadusraamatu preemia saanud raamat „Kasvatus ökokriisi ajastul“ („Kasvatus ekokriisin aikakaudella“) pakub eestlastele võimaluse teha taastutvust kasvatuse mõistega, seda põletava, ajakohase, isegi fataalse ilmingu tähenduses ning nüüdisaegse kasvatusteaduse võtmes. Raamatut tõlgitakse ja see on ilmumas ka eesti lugeja jaoks. Kui lugeja soovib näha avanemas suurt pilti, kus paistab kätte planeedi saatus põimituna inimese kujunemislooga, siis selle ta siit leiab. Raamat sobib eri valdkondade teadlastele, üliõpilastele, õppejõududele, õpetajatele, kõigile filosoofiliste kalduvustega loodushoidlikele inimestele, kes suudavad nautida elegantset teksti abstraktsel tasandil.

Meie hektiline aeg, mil juubeldused tehnoloogiliste saavutuste üle vahelduvad apokalüptiliste meeleoludega planeedi ja kogu inimkonna saatuse pärast, mil inimese vägevuse imetlemine vaheldub tema nõtruse ja viletsuse üle ahastamisega, on pannud küsima: kuidas me sellisesse olukorda sattusime? Kuidas me sellisteks saime? Meid aidatakse sedasorti äratundmiseni, mis on leidnud sõnakujuna väljenduse ka ühe varasema kuulsa raamatu pealkirjas: alguses oli kasvatus (Alice Miller, „Am Anfang war Erziehung“). Teadmine lähenevast kliimakatastroofist, väljasurevatest liikidest, inimese ahnest ja hoolimatust ringikäimisest loodusressurssidega on arvatavalt jõudnud kõigi rahvaste teadvusse, kus võib rääkida meedia ja üldhariduse olemasolust. Inimene on 
vallandanud jõud, mida ta enam ei valitse. Põhjalikult ja kirgliku sulega laotab Veli-Matti Värri lugeja ette panoraami, kuidas hiliskapitalismi ning tehnoloogilise tsivilisatsiooni oludes on inimeste suhestumine looduse ja looduga kujunenud isekalt röövellikuks, kuidas taasluuakse ökoloogiliselt jätkusuutmatut eluviisi ning milline osa on selles kõiges sellisel inimkonna saavutusel nagu haridussüsteem. Kasvatus oli alguses, on praegu ja loob tulevikku, nagu ta seda on kogu aeg teinud. Isegi siis, kui mõnel maal tõrjutakse ta vähetähtsaks koduterminiks.

Kas tulevik on inimese jaoks olemas? Küsitavaks on saanud terve valitsev eluvorm, kuhu ka kasvatus on meid toonud. Ning vajadus sellest lahti öelda, mis on samuti võimalik eelkõige kasvatuse kaudu.

Raamatu tonaalsusest, masendusest ja lootusest annavad esmase aimuse peatükkide pealkirjad: Virmajõgi on surnud, kas sureb ka meie planeet? Kasvatus inimkonna looja ja võimu vahendina? Kasvatus on osa kultuurilisest tähendushorisondist. Kasvatus ideoloogiliste hegemooniate haardes. Inimese dualistlik olemus on tema loodussuhte võti. Soovide ontoloogiline eelisõigus. Inimene kui soovide olend. Miks oleme koopas? Kuidas pääseda koopast välja? Progressi petlik lummus. Ökoloogilise kasvatustarkuse lähtekohti. Miks on ülikoolid osa ökokriisist? Me ei peaks hülgama seda, mis on inimeses parimat.

Analüüsi mitmetasandilisus ning ka seda läbiv ühtlane peajoon põhineb rikkalikul soome kasvatusteaduslikul mõttetraditsioonil, ent ka maailma mastaabis tuntud teoreetikute tööde tõlgendustel, kellest peamised on Maurice Merleau-Ponty, Jacques Lacan, Slavoj Žižek ning kriitilise teooria mõttetraditsiooni klassikud.

\section{Kasvatuse osast planeedi saatuses}

Lugeja teadvuses leiab värskendamist tõsiasi, et kasvatusprotsessides kujuneb inimese maailmavaade, maailmasuhe ja maailmapilt, mis väljenduvad tema valikutes ja tegudes. Ning siit omakorda vastasmõju laiema ühiskondliku fooniga. Ja et praegu on see olemisohtlik. Lugejale tuletatakse meelde, et nii nagu kasvatusse on aastatuhandeid kuulunud eetika ja moraali küsimused, on inimene käsitatav moraalisubjektina ka tänapäeval, isegi kui globaalsetes tuultes on see majanduskasvu häiriv tühiasi unustusse pühitud. Kasvatus on läbi põimunud ajastuomase sotsiaalkultuurilise kontekstiga, selle ideoloogiate, aadete ja võimusuhetega. Seega kujuneb kasvatuse väärtuseline vaatenurk nii traditsioonide kui ka valitsevate hegemooniate mõjudes. Igal ajastul valitseb oma tähendushorisont sellest, mis on pürgimisväärne, mis õige ja vale, mida inimene tohib, milline on tema koht ja kus on võim. Ajastuomane eluviis on kasvavale inimesele see, millesse ta sünnib, ning selle normaalsused ning 
enesestmõistetavused suunavad tema suhtumisi ja hoiakuid. Sellega suhestudes saab suunad ka kasvatus ja kujunevad arusaamad, milline on soovitud inimene, taotlemisväärne hea elu ning hea kasvatus. Praegune suund on kandnud läänemaailma individualismi, hedonismi ning ühemõõtmelise majanduskasvu teenistusse.

Kui soovime luua head inimlikku väärtuslikku elu, on selles eriline osa kasvatusel kui ühiskondlikul praktikal. Ent kasvatust tuleb vaadelda kriitiliselt, teadvustades, milliseid jõude ja milliste vahenditega ta teenib. Kasvatusel on kalduvus saada osaks hävingut põhjustavate jõudude loogikast. Autor väidab, et kui kasvatus- ja sotsialisatsioonikogukonnad mugavnevad kriitikavabalt valitseva hegemoonilise tahte täidesaatjateks, olles pelgalt kellelegi vahendid, osalevad nad elu hävitava maailmakorra säilitamisel.

\section{Mida saab lugeja teada kasvatuse enese kohta?}

Ta saab teada, kuidas see meil vananenuks kuulutatud mõiste on eredalt nüüdisaegsete sündmuste põhjusi valgustav. Veli-Matti Värri liigub fenomenoloogilises mõistestikus, püüdes kirjeldada kasvatuse kui ilmingu olemuslikke piirjooni ning seotust kultuuri ja ühiskonnaga. Kohtume mõistetega eelmõistmine ja tähendushorisont, mis on igaühel olemas enne teadvustatud toiminguid. Eelmõistmine annab piirjooned ja sisud, mis on ette antud inimese elusituatsioonist ja millest areneb teadvustatud mõistmine. Individuaalsed ja kollektiivsed tähendushorisondid võivad selgitada tegelikkust adekvaatselt, ent ka sisaldada väärastunud arusaamu. Horisondid on mõistmiskontekstid, mille sisu tõlgendades nähakse oma võimalusi. Praegu on ühiskondade tähendushorisondid märgistatud tehnoloogilisest maailmapildist.

Kasvatuse põhiküsimusi on inimkäsitus, sest kasvatuses püütakse alati teostada mingisuguseid inimesele suunatud ideaale ja eesmärke, milles ühtaegu väljendub arusaam inimesest. Need on ontoloogilised oletused näiteks subjektist ning sellest, kuidas subjekt suhestub sotsiaalse tegelikkusega. Kasvatus on tulevikku suunatud, ent olevikust märgistatud, ta on seotud ühiskondade tähendushorisondi ning eetosega, ideoloogiate ja majanduspoliitiliste eesmärkidega. Kasvatuses on nii utoopiline mõõde kui ka lootuse perspektiiv, siin kätkeb niihästi võimalus maailma kahjustamiseks kui ka tema uuendamiseks.

Haridus on võimalik vaid kasvatuse kaudu. Kasvatuse ülesanne on edendada kasvava inimese haridusprotsesse (sivistys), see tähendab täiustumist üldinimlikes kvaliteetides ning arengut iseseisvaks subjektiks, kes on võimeline uut loovaks produktiivseks tegevuseks. Kasvades toimub ühtaegu nii inimese individualiseerimine kui ka sotsialiseerumine. Ent kasvatus ei samastu sotsialisatsiooniga, mis on normide, reeglite, toimimisviiside jne omaksvõtt, ta on 
enamat. Kui sotsialisatsiooniprotsessides vahendatakse olemasolevat säilitavaid eluvorme ja mõtteviise ja taotluseks on nende omaksvõtt, siis kasvatuse kaudu avaneb vabaduse perspektiiv „saada selleks, kes oled“.

Veli-Matti Värri teeb nähtavaks kasvatuse koha kogu ühiskondlik-kultuurilises totaalsuses, tutvustades saksa kasvatusteadlase Dietrich Benneri ühiskonna tervikut hõlmavat mudelit $\mathrm{n}$-ö praktilise elu vältimatustest, milleks on töö, mõjusuhted (mida reguleerib eetika), poliitika, esteetika, religioon ja kasvatus. Kõik nad on läbi põimunud kasvatusest kui erilisest inimlikkust loovast eluvormist. Kasvatus kui väärtuste kandja ning edastaja suhestub samas muude eluvaldkondade väärtusvormide ja ühiskonna osasüsteemidega, püüdes inimest nendega kohandada. Mida unustada ei tohiks, on kasvatuse kaksikloomus - ta on ühelt poolt inimlikkuse looja ning teiselt poolt võimu vahend, mis äärmusjuhtudel võib inimlikkuse hävitada. See võimaldabki ühiskondlikul hegemoonial teha kasvatus tihti oma käepikenduseks.

Igale ajajärgule on iseloomulik n-ö moraalikosmoloogia, mis tähendab, et inimese kujunemist ja identifitseerumist valitseb teatud moraalne kood, mis on rahvuse sidususe loomise lähtekoht. Autor näitab põgusa ülevaate kaudu õhtumaise kasvatuse-hariduse mõtteloost, kuidas oleme jõudnud praegusesse olukorda. Inimese ja looduse vastandumise algus pärineb juba antiikajast. Valgustusajastu ideaalide jälgedes sai dualistlik vaade subjekti ja objekti vastamisi ja eraldi olemisest valitsevaks ja inimene kuulutas end looduse krooniks. Haridus pidi olema see, mille abil inimene saab enese käsutusse vahendid, et vabaneda looduse seatud piirangutest, saada oma käsutusse loodusseadused ja nende abil ka loodusjõud. Kasvatusest lähtub nendega ringikäimine ehk vastutus.

Autor kasutab mõistet koopametafü̈̈sika, mõeldes selle metafooriga argiteadvusest alateadvusse tõrjutud teatud elu- ja mõtteviise ning probleeme, millega me tegelda ei soovi. See eemaldab meid vastutusest muuta oma eluviise ja suhet loodusse, olemisse ning aega. Metafooril on konkreetne materiaalne vaste, see on kaljude alla koobastesse peidetud tuumajäätmed, mille tappev toime ei kao ka miljonite aastatega. Meie tsivilisatsiooni valitsevad käsitused, tegevuspõhimõtted ja eesmärgid põhinevad kultuuri nähtamatuks aluseks olevatel metafüüsilistel käsitustel, nagu selleks on arusaam inimese ja looduse suhtest. Probleemide lähtekohaks peab Värri metafüüsilistes süvastruktuurides kinnistunud moraaliidentiteeti, mida pelgalt välised väärtusjutud ning üleskutsed ei muuda. On vaja jõuda mõistmiseni, millistel uskumustel ja alateadvuslikel põhimõtetel ning narratiividel põhinevad meie tegusid suunavad käsitused. Selleks on vaja minna teadmise taha, psühhodünaamilisele tasandile, et mõista meie soove ja ihasid liikuma panevaid jõude. 
Miks on võim kasvatusse põimunud? Juba algupäraselt on see kasvatuses eneses olemas, sest tegu on ebavõrdsete suhtega. Seda väljendab mõiste pedagoogiline paradoks - ideaalides tahaksime kasvatada inimese vabaks ja autonoomseks, et ta saaks iseeneseks ja vabaneks võõra äramääratusest, teisalt eeldab lapse spontaansus ja ebaküpsus piiranguid vabadusele, $n n$ harivat distsipliini (sivistävä kuri), mille läbi sotsialiseeritakse inimene ühiskondlike normide sisse, sealjuures aga ka valitsevale ideoloogilisele korrale sobivaks. Kes ja kuidas seab mõõdu ja suhte nende vahel? See väärib alalist teravapilgulist analüüsi, mitte kasvatuse enese ärapeitmist koopasse, sest teda häbenetakse.

Tuleb pidevalt teaduse ja filosoofia mõtlemiskultuuri vahendite abil diagnoosida, millises olekus on kasvatus kui inimlikkust loov kultuuriline praktika ja kuidas kasvatust kaitsta. Pole imekspandav süsteemide kiusatus näha kasvatust vaid vahendilisena ja mitte tunnistada, kuidas kasvatus on suhteliselt iseseisev ja eriline inimeseks olemisega kaasnev fenomen, mis kätkeb eneses üsna erinevaid arengusuundi.

\section{Kuidas kasvatuse läbi taastoodetakse hukatuslikku eluviisi?}

Kui kasvatusest on saanud vahend valitseva hegemoonia käsutuses, et inimesi alistada ja muuta oma tööriistaks, on kasvatus ise osa sellest probleemist, mida tajume kui ohtu inimkonnale ja kogu planeedile. Nii väidab autor. Foucault'likust perspektiivist on sotsialiseerimise aluseks valitsemise tehnikad, mille varjatud eesmärk on toota enesevalitsemise tehnikaid, et inimene tahaks ise olla selline, nagu temast oodatakse.

Edasi annab autor pildi, millised moraalsed koodid on suunanud soome hariduse ja kasvatuse mõttelugu rahvusteadvuse ärkamisest kuni tänapäevani, kuidas need on muutunud ja mil viisil pääses mõjule uusliberalistlik konkurentsiagenda. Inimpilt on muutunud dramaatiliselt, üleindividuaalsest rahvuslikust kodanikukäsitusest siirduti neoliberalistliku tarbiva indiviidini. Muutunud on ka indiviidi ja ühiskonna suhe. Indiviidi moraalseid omadusi rõhutav hüve-eetiline mõtlemine on asendunud tema sooritusvõime ja muude konkureerimisele omaste tunnuste esiplaanile asetamisega. Kui rahvusriigi liikmeid ühendavas protestantismist mõjustatud väärtussüsteemis oli töö inimese peamine ülesanne, siis nüüd oleme jõudnud konsumeristlikku ajastusse. Kohustuste koodist siirduti elama identiteetide katsetamise, naudingute ja tarbimise koodi kohaselt. Oled see, mida tarbid.

Värri loob pildi, kuidas on uusliberalistlik ideoloogia moonutanud kogu kasvatuse maailma arusaamu. Kuivõrd mõjud on globaalsed ning nende vaadete levitamiseks kasutatud kõiki nüüdisaegseid vahendeid, on raske neile vastanduda. Hilismodernset maailma iseloomustab toodangumaailma 
ontoloogia, mis on laienenud üle kõigi inimelu sfääride. Selle, mis on tähtis, määrab majanduslik-tehniline protsess.

Toodangumaailma ontoloogia aluseks on inimese minasuse, eelkõige tema soovide ja tahtmiste vormimine tootemaailma huvidele vastavaks. Infotehnoloogiline majandus koos eluaegse õppimise ideoloogiaga on saanud nimetuse psühhokapitalism, millest on läbistatud kogu praegune eluviis. Panus on tehtud inimesele kui soovide olendile. Hariduse õigustus on majanduslikult kasuliku inimkapitali tootmine. Suhet tulevikku iseloomustab eesmärgiratsionaalne ajakäsitus, kasumõtlemine, kalkuleeriv omamisiha. Majandusmõtlemisel põhinevad võimusuhted põimuvad ideoloogilissümboolsete struktuuridega. Konkurents arvatakse olevat ühiskondliku elu põhisammas. Koolimaailm toodab eluhoiakuid, mis tingib vahendilise suhte nii loodusse, teistesse inimestesse kui ka iseendasse, õpitavat suunab kasu- ja tarbimismõtlemine. Lisaks sellele, mida tarbida, toodetakse vajadust tarbida.

Hariduseetose alus ei ole haritus, vaid konkurentsivõime edendamine, mis toidab tarbimiskeskset idealismi. Ent konkurentsimaailm ei loo solidaarsust, ei moraalsust, ei kiiduväärseid iseloomujooni, mille abil muuta praegust jätkusuutmatut eluviisi.

Teoreetilistes teemaarendustes toetub autor Merleau-Ponty põimumisontoloogiale (kietoutuneisuuden ontologia) ja sel põhinevale käsitusele inimese seotusest kõige elavaga, siit jõuab ta inimese eelteadvusliku maailmasuhteni, mille võimsamaid komponente on soovid (tahtmised, himud, ihad, isud). Soov (halu) on raamatu üks võtmekäsitus, mille abil on võimalik mõista praeguse eluviisi problemaatika põhjusi. Algselt on inimese maailmasuhe subjektsusvaba, see on loomulik reflekteerimata olemine algupärases vitaalses loodussuhtes, mis eelneb meie saamisele mõistusolenditeks. Soovide-tahtmiste kaudu luuakse Merleau-Ponty järgi ühendus teiste kehaliste olendite maailmadega. Sooviva keha naudingut taotlev intentsioon avaneb tegelikkusse, see on kehalisusele omane eksistentsiaalne maailmasuhe, milles avaldub elu manifestatsioon loovuse, viljakuse, rikkalikkuse ja erootilisuse kaudu.

Inimese kujunemise ja ühiskonna mõjusuhet analüüsides on pööratud vähe tähelepanu, kuidas inimeste soovide-olemus sotsialiseeritakse valitsevatesse ideoloogilistese struktuuridesse ja kuidas eri ühiskondade reeglistik inimese soovide-tahtmiste ala võimustruktuuride huvides suunab. Ajalukku tagasi vaadates suunati kord inimene askeesi - soove-ihasid patuks lugedes, siis kultiveeriti naudingute edasilükkamist tulevikku, heroiseerides kasinust. Uusliberalistlikus majandusfundamentalismis kultiveeritakse usku, et inimlik onn ja vabadus saavutatakse turu abil. Praegune inimelu suund on vahetutele naudingutele, lõpmatule küllastumatule tarbimisele, äratatud on omamiskirg. Ka eneseteostus ja identifitseerumine toimivad tarbimise 
kaudu. Nauding seotakse ka õnnestunud sooritusega. Nii luuakse vastavaid teadvuse vorme, mis inimest vangistavad ja tingivad võõrandumise loodusest, ühiskonnast, lõpuks ka iseenesest. Ideoloogilis-majanduslikult toodetud soovidel on kollektiivne struktuur. Kõige selle nimel toimib meediatööstus, reklaam, üleilmsed võrgustikud. Sama ideoloogilise masinavärgi osaks on ka haridusinstitutsioonid. Värri analüüsib, kuidas palju ülistatud eluaegne õppimine on vastuoluline, kuivõrd on samas sundtegevus äraelamiseks toodangumaailma nõuete päraselt, mis tekitab üksikisikus jätkuvalt ebapiisavuse tunnet ja enesemääramiskogemuse kadumist. Värri: „Selle asemel, et ebatäiuslikkust, haavatavust ja poolikust aktsepteerida kui inimese juurde kuuluvaid loomulikke tunnusjooni, on meie kultuurile omane, et tulevikku siiratakse järjest suuremad täiuslikkuse ootused. Turuloogikat järgiv eluaegse õppimise ideoloogia on siin hea näide: alalises puudulikkuses elav soovide subjekt ..." (lk 110)

Kasvatusinstitutsioonide praegused ülesanded tuleb seada küsitavaks. Milliseid inimesi me kasvatame? Millisesse maailma? Millistel eeldustel?

\section{Kuidas on kasvatuse abil võimalik toimuvat muuta?}

Autori peamine väide ja raamatu kirjutamise mõte on, et peamised käsitused inimese ja looduse suhtest tuleb ümber mõtestada, kui soovime elu jätkumist maakeral. Ökoloogiliselt jätkusuutlik maailmasuhe nõuab uusi globaalseid eetilisi norme. Vaja on uut visiooni, ökoloogiliselt vastutustundlikku maailmapilti, uut mõistmishorisonti. Pääsemine hävingu teelt eeldab lahtiütlemist toodangumaailma hegemooniast ja inimese maailmas olemise viiside ringimõtestamist. Ökoloogilist mõtlemist ei saa lahutada inimlikkusest ega inimese põhivajadustest, selleks vajaksime ökoloogilist haridust. Praeguse eluviisi muutmine eeldab inimese soovide-tahtmiste struktuuri mõistmist ja soovide suuna mõjutamist.

Kuidas aga mõjustada psühhokapitalistlikku soovide tootmise struktuure ja muuta soovide suunda? Soove on võimalik ning nüüd ka vältimatu õilistada pedagoogiliselt - nii indiviidi kui ka ühiskondlikul tasandil. „Ökoloogiline situatsioon nõuab inimkesksuse ületamist ja kaastunde ning vastutustunde kui pedagoogiliste hoiakute laiendamist ka loodusele väljaspool inimest.“ (lk 108)

Autor soovitab uut kasvatustarkust, mille kese on ökoloogiline mõtteviis. Kasvatus ja haridus ei tohiks enam olla osaks ökokriisist, vaid teadlikult sellest inimese eemale viima. Värri kutsub üle vaatama senise progressimõtlemise kivisse raiutud printsiibid, sealhulgas Bildung'i-mõtlemise utoopilise pärandi, ja teadvustama, kuidas psühhokapitalism on kaaperdanud kasvatusmõtlemise humanistlikud õilsad põhimõtted sotsialiseerimise vahendiks. 
Traditsiooniliselt oli nende põhimõtete keskmeks püüd hea elu poole - ent hea elu on nüüd määratud ajastuomase ideoloogilise hegemoonia ettekirjutistega, ja selle tunnusjooned on taandatud tarbimisnaudinguteks. Muuta tuleb enesestmõistetavateks loetud elupraktikaid ja uskumusi. Inimese vastutus uues loodussuhtes eeldab loobumist omamishimulisest antropotsentrilisest maailmapildist, mis on käivitanud soovide ratta.

Värri arvates tuleks alustada harjumuspäraste seisukohtade ümbermõtestamisest eelkõige kasvatusteadustes. Ta pakub välja kriitilise kasvatusteaduse vaatenurga meie teoreetiliste aluste ontoloogiliseks analüüsiks ning sotsialiseerimise enesestmõistetavuste nähtavaks tegemiseks, näiteks selle, kuidas toodetakse psühhokapitalistlikku soovmõtlemist, kuidas harjumuspärane kasvukeskkond on laetud tarbimis- ja naudinguideoloogia kuvanditest, kuidas tekitatakse ihasid. Kui kasvatusmõtlemine on oma alustes nõrk, ei ole võimalik ka mõista, mida kasvatus ja lapse väärtus tähendavad.

Kasvavas inimeses eneses on algupärased eeldused selleks olemas. Lapsel on olemas algupärane vitaalne kaastunne, milles leiame potentsiaalidena väärtushorisondi kõik liigid vitaalsetest esteetiliste, eetiliste ja pühadusväärtusteni. Eetilisuse arengupsühholoogilise lähtekoha leiame lapse eelkeelelises aistingute maailmas, milles areneb teiste olendite taju. Siit areneb kaasteelise tunne, kaastunde eetika ning soovide kultiveerimine ökoloogilisele tarkusele suunatud pedagoogika abil. Algupärasest seotusest loodusega saab luua elavaid kogemusi, et siit areneks kaastunne kogu oleva vastu. Et inimeses kujuneks veendumus elu väärtusest ja oma olemasolemise mõttest, tuleb teda tunnustada tema olemasolus.

Kasvatuse ülesanne on alati moraaliressursside ja eetilise kujutlusvõime areng, millest lähtub enesekasvatus ehk vastutus omaenese kasvu eest ning ka vastutus teiste olemise eest. Teadmine loodussuhtest ja selle poolelt asetatud vastutusest on vaja tuua tagasi kasvatusmõtlemisse. See, mida teeme loodusele, teeme iseenesele. Kasvatuskogukondi peaksid juhtima märksõnad nagu empaatilisus tema variatsioonides, kasvatusvastutus, tunnustussuhe, tasakaalustatud areng. Ja teadlikkus vajadusest katkestada praegust olukorda taastootvad seosed.

Kasvatuse mõiste abil on võimalik haarata inimolemise tervik, sidudes siia ka tema suhestumised ja teod nii looduses kui ka kultuuris. Hariduse mõiste abil see võimalik ei ole. Iga uus ilmakodanik on võimalus igasugusteks arenguks, ning seda saadab ja kujundab kasvatus. Veli-Matti Värri raamatus saab see ehedalt ja eksistentsiaalselt nähtavaks. 